\title{
Choroidal Mast Cells in Retinal Pathology
} A Potential Target for Intervention

\author{
Elodie Bousquet, ${ }^{* \dagger}$ Min Zhao, ${ }^{*}$ Brigitte Thillaye-Goldenberg, ${ }^{*}$ Viera Lorena, ${ }^{*}$ Beatriz Castaneda, ${ }^{*}$ Marie Christine Naud, ${ }^{*}$ \\ Ciara Bergin, Bernadette Besson-Lescure, ${ }^{\Uparrow}$ Francine Behar-Cohen, ${ }^{* \dagger \S}$ and Yvonne de Kozak*
}

\begin{abstract}
From INSERM UMRS1138, * Team 17: Physiopathology of Ocular Diseases: From Physiopathology to Clinical Developments, University of Paris Descartes, Sorbonne Paris Cité, Sorbonne Universities, UPMC Univ Paris 06, Cordeliers Research Center, F-75006, Paris, France; the Department of Ophthalmology, ${ }^{\ddagger}$ Hôtel-Dieu of Paris, Assistance Publique Hôpitaux de Paris, Sorbonne Paris Cité, Paris, France; the Department of Ophthalmology of Lausanne University, Jules Gonin Ophthalmic Hospital, Lausanne, Switzerland; and the Technologic platform of phenotypage of small animals, ${ }^{\mathbb{1}}$ IFR65/IRSSA, Saint-Antoine Hospital, Paris, France
\end{abstract}

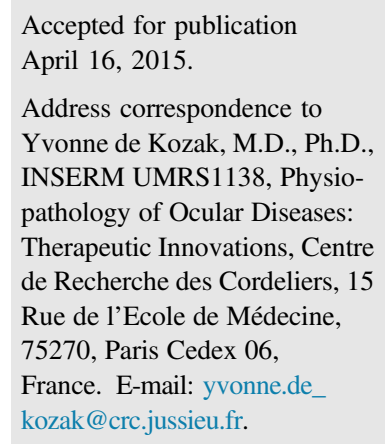

Address correspondence to Yvonne de Kozak, M.D., Ph.D., INSERM UMRS1138, Physiopathology of Ocular Diseases: Therapeutic Innovations, Centre de Recherche des Cordeliers, 15 Rue de l'Ecole de Médecine, 75270, Paris Cedex 06, France. E-mail: yvonne.de kozak@crc.jussieu.fr.

\begin{abstract}
Mast cells are important in the initiation of ocular inflammation, but the consequences of mast cell degranulation on ocular pathology remain uncharacterized. We induced mast cell degranulation by local subconjunctival injection of compound 48/80. Initial degranulation of mast cells was observed in the choroid 15 minutes after the injection and increased up to 3 hours after injection. Clinical signs of anterior segment inflammation paralleled mast cell degranulation. With the use of optical coherence tomography, dilation of choroidal vessels and serous retinal detachments (SRDs) were observed and confirmed by histology. Subconjunctival injection of disodium cromoglycate significantly reduced the rate of SRDs, demonstrating the involvement of mast cell degranulation in posterior segment disorders. The infiltration of polymorphonuclear and macrophage cells was associated with increased ocular media concentrations of tumor necrosis factor- $\alpha$, CXCL1, IL-6, IL-5, chemokine ligand 2, and IL-1 $\beta$. Analysis of the amounts of vascular endothelial growth factor and IL-18 showed an opposite evolution of vascular endothelial growth factor compared with IL-18 concentrations, suggesting that they regulate each other's production. These findings suggest that the local degranulation of ocular mast cells provoked acute ocular inflammation, dilation, increased vascular permeability of choroidal vessels, and SRDs. The involvement of mast cells in retinal diseases should be further investigated. The pharmacologic inhibition of mast cell degranulation may be a potential target for intervention. (Am J Pathol 2015, 185: 2083-2095; http://dx.doi.org/ 10.1016/j.ajpath.2015.04.002)
\end{abstract}

Mast cells are detected in the lids, conjunctiva, and the uveal tract (iris, ciliary body, and choroid) of several different species. $^{1-4}$ In humans and rats, mast cells are abundant in the anterior and posterior uvea but absent in the retina. ${ }^{5}$ These cells are understood to originate from hematopoietic progenitors and after migration to vascularized tissues to mature locally. ${ }^{6}$ Mature mast cells have a role in hypersensitivity reactions and express on their cell surface the high-affinity IgE receptor, complement receptors, and Tolllike receptors. 6,7 The cross-linking of high-affinity IgE receptor with IgE-antigen induces the release of molecules present in mast cell granules such as histamine, serotonin, prostaglandin $\mathrm{D}_{2}$, and leukotriene $\mathrm{B}_{4}$. These mediators are released during the early period of the inflammatory reaction and lead to the release of other inflammatory mediators. Besides, IgE-independent activation of mast cells is effective in nonallergic reaction. In these conditions, mast cells are activated by pathogen-associated molecular patterns, complement, cytokines, hormones, and physical activators. ${ }^{7,8}$ This activation results in the release of cytokines and chemokines. It is understood that the fusion of secretory granules with the plasma membrane results in the quick

Supported by the Fondation pour la Recherche Médicale (E.B.)

F.B.-C. and Y.d.K. contributed equally to this work as senior authors.

Disclosures: None declared. 
release of a number of cytokines and vasoactive amines such as histamine, contributing to the recruitment of neutrophils. ${ }^{9}$ As such, mast cells initiate immune responses, in cases such as allergic disorders and immune responses to pathogens. ${ }^{6,10,11}$

In the eye, degranulation of chorohidal mast cells was shown to contribute to the early onset of experimental autoimmune uveoretinitis (EAU). ${ }^{4,12}$ However, degranulation of mast cells by using compound 48/80 injected 2 days before the immunization prevents the development of ocular inflammation. ${ }^{12}$ When inhibitor of mast cell degranulation is topically instilled from the fourth day after immunization, EAU is delayed and its severity is reduced. ${ }^{12}$ However, mast cells do not seem to contribute to the pathogenesis of experimental melanin-induced uveitis, another relevant model of uveitis, suggesting that the stimulus intervenes in the type of reaction. ${ }^{13}$ In endotoxin-induced uveitis (EIU), the implication of mast cells remains controversial. The intensity of EIU is decreased in rats treated with compound $48 / 80$ before the induction of uveitis. ${ }^{14}$ However, the severity of EIU is not decreased in mast cell-depleted DBA $/ 2$ mice. ${ }^{13}$ Other teams showed a positive correlation between choroidal mast cells numbers and EAU ${ }^{15}$ or EIU ${ }^{16}$ susceptibility in a number of rat strains. However, PVG rats with the lowest choroidal mast cell number are still susceptible to EAU. ${ }^{3}$

In contrast, mice deficient in mast cells were resistant to developing arthritis, and the disease was restored by mast cell engraftment, demonstrating a direct role for mast cells in the pathogenesis of inflammatory arthritis. ${ }^{17}$ Further, in experimental models of multiple sclerosis, bullous pemphigoid, and rheumatoid arthritis, the role of mast cells as promoters of disease severity with increase of tumor necrosis factor (TNF) and/or neutrophil recruitment was reported. ${ }^{18}$ So, according to the disease, the experimental animal, and the time after onset of disease, mast cells may be differentially implicated.

Compound 48/80 was first characterized as a selective histamine releaser from mast cells ${ }^{19}$; it is a condensation product of $p$-methoxyphenetylamine and formaldehyde widely used for non-IgE-dependent stimulation of mast cells. Compound 48/80 activates and induces degranulation of mast cells. Besides this effect, different actions of compound $48 / 80$ were reported such as action of excitation of capsaicin-sensory nerves,${ }^{20}$ interaction with the nicotinic receptor/channel complex to decrease ganglionic transmission, ${ }^{21}$ and activation of enteric nerves. ${ }^{22} \mathrm{Com}-$ pound 48/80 does not act exclusively on mast cells; however, it is reported that injection of compound $48 / 80$ mediates hyperalgesic responses (edema, pain, and neutrophil influx) in wild-type $\mathrm{C} 57 \mathrm{BL} / 6$ but not in genetically mast cell-deficient C57BL/6-KitW-sh/W-sh mice. ${ }^{23}$ Further, the response can be restored in a mast cell-dependent manner.

In human pathology, serous retinal detachments (SRDs) are often observed in eyes with ocular inflammatory disorders such as Vogt-Koyanagi-Harada disease. ${ }^{24}$ However, multiple mechanisms may lead to SRD, because they also are present in other ocular disorders such as central serous chorioretinopathy and wet age-related macular degeneration (AMD). ${ }^{25}$ In wet AMD, for example, genetic studies have found that complement alternative pathway activation is associated with increased prevalence of the disease. ${ }^{26-28}$ Deposits of C5a, a potent mast cell degranulating component, ${ }^{29}$ were detected in the choroid and retinal pigment epithelium (RPE) of eyes with $\mathrm{AMD},{ }^{30}$ suggesting that mast cells may be a complement pathway effector in AMD pathogenesis.

To clarify the direct role of mast cells in ocular disorders, we examined the effects of specific ocular mast cell degranulation in rats by the local unilateral subconjunctival injection of the synthetic compound 48/80.

\section{Materials and Methods}

\section{Animals}

Adult female Lewis rats (6 to 8 weeks old; Janvier, Le Genest-Saint-Isle, France) were used in this study. Rats were housed in a 12-hour light and 12-hour dark cycle and fed water and dried ration ad libitum. Experimental procedures were submitted and approved by the ethic committee of Paris Descartes University (number Ce5/2012/122). The care and use of the rats were in compliance with the statement for the Use of Animals in Ophthalmic and Vision Research (accreditation number of the laboratory: B 750602 ) by the Association for Research in Vision and Ophthalmology.

\section{Injections}

Rats were anesthetized by intraperitoneal injection of pentobarbital $(25 \mathrm{mg} / \mathrm{kg}$ Nembutal; Abbot, Saint-Remy sur Avre, France). One drop of $1 \%$ tetracaine (Sigma-Aldrich, Saint Quentin Fallavier, France) was instilled for local anesthesia.

\section{Subconjunctival Administration of Compound 48/80}

Doses of compound $48 / 80$ of 1 to $120 \mu \mathrm{g}$ were tested previously. ${ }^{4,12}$ One microgram of compound $48 / 80$ induced a partial degranulation of choroidal mast cells after $30 \mathrm{mi}-$ nutes, and the mast cell degranulation increased with higher doses of compound 48/80 injected. Because after injection of the highest dose tested $(120 \mu \mathrm{g})$, all mast cells were constantly degranulated in the injected eye, whereas all mast cells were normal in the contralateral non-injected eye, this dose was chosen.

In the present study, one subconjunctival injection of compound 48/80 ${ }^{12,14}$ (Sigma-Aldrich; $120 \mu \mathrm{g}$ of compound $48 / 80$ in $100 \mu \mathrm{L}$ of sterile pyrogen-free $\mathrm{NaCl} 0.9 \%$ ) was performed in the right eye in the temporal site of the conjunctiva as previously described ${ }^{12}$ with the use of $1-\mathrm{mL}$ syringes with 30-gauge needle. Left eye was not injected. 
Subconjunctival Administration of Sodium Chloride

Control rats were injected subconjunctivally with vehicle $(\mathrm{NaCl} 0.9 \%)$.

\section{Subconjunctival Injection of DSCG}

Disodium cromoglycate (DSCG; cromolyn sodium salt; Sigma-Aldrich) blocks the release of mediators from mast cells. ${ }^{6}$ One subconjunctival injection of DSCG (2 mg DSCG/rat weighing $200 \mathrm{~g}$ dissolved in $100 \mu \mathrm{L}$ of $\mathrm{NaCl}$ $0.9 \%$ ) was administered in the right eye at the nasal site 15 minutes before the subconjunctival administration of compound $48 / 80$ performed at the temporal site. Control rats received one subconjunctival injection in the right eye of sterile pyrogen-free $\mathrm{NaCl} 0.9 \% 15$ minutes before compound 48/80. Left eye was not injected. Rats were examined by optical coherence tomography (OCT) at different time intervals from 15 to 30 minutes up to 24 hours and then at 1 month. Abnormal modifications of ocular tissues were analyzed by histologic examination performed at 1 month.

\section{In Vivo Investigations}

\section{Clinical Examination}

Eyes were examined with a biomicroscope (slit lamp) at regular time intervals in compound 48/80-injected eyes, in contralateral noninjected eyes at 10 to 30 minutes, 1 hour and 2, 3, 4, 5, 7, and 24 hours after subconjunctival injection of compound 48/80. At each time point, the conjunctiva, lens, iris, pupil, and the anterior chamber were observed. Pupillary dilation was obtained after administration of a drop of mydriaticum (Thea, Clermont Ferrand, France). The severity of the reaction to the subconjunctival injection of compound 48/80 took into account each ocular inflammatory sign as follows: vasodilation of iris vessels, myosis, fibrin exudate, hypopion, iris hemorrhages, and synechiae. Presence of each sign was encoded as 1 and absence as 0; the severity of the response was evaluated in each eye by the sum of the inflammatory signs per eye. Alteration of the lens transparency (cataract) was also evaluated.

\section{Optical Coherence Tomography}

The assessment of rat retina and choroid was performed on anesthetized rats by using spectral domain OCT (Spectralis device, Heidelberg, Germany) adapted for small animal eyes. ${ }^{31}$ Pupils were dilated with 5\% tropicamide drops. Scans were taken in the same rats before treatment and at 1 hour and 3,6 , and 24 hours after subconjunctival injection of compound 48/80. Each two-dimensional B-scan recorded at $30^{\circ}$ field of view consisted of 1536 A-scans with an optical resolution that reached $3.5 \mu \mathrm{m}$, and the enhanced depth imaging option was used to evaluate the choroidal layer. ${ }^{32}$

\section{Ex Vivo Investigations}

Experimental groups of rat eyes were as follows: compound 48/80-injected eyes, contralateral noninjected eyes, and sodium chloride-injected eyes, enucleated at four time points after compound 48/80 injection at 1 and 3, 6, and 24 hours. Number of experimental eyes is indicated in figure legends.

\section{Flat-Mounted Preparations of the Choroid for Staining and Quantification of Choroidal Mast Cells Degranulation}

Choroidal mast cell staining was performed as previously described. ${ }^{4}$ Briefly, under stereomicroscope, the retina was removed, and the choroid and the adhering sclera were placed into a fixative solution that contained anhydrous acetic acid $/ 95 \%$ ethanol $/ 40 \%$ formalin/distilled water at 1:15:6:30. All through the experiment, tissues were passed individually from one reagent to another. After 60 minutes of fixation, the choroid was detached from the underlying sclera, washed in $95 \%$ ethanol, and stained for 40 minutes in $0.25 \%$ solution of toluidine blue in $70 \%$ ethanol acidified with hydrogen chloride ( $\mathrm{pH}$ 2.4). Choroids were dehydrated, folds were removed under the stereomicroscope, and choroids were mounted in Eukitt (VWR, Fontenay-sousBois, France). Under these staining conditions, only mast cell granules were stained.

\section{Choroidal Mast Cell Staining}

Under stereomicroscope, the retina was removed, and the choroid and the adhering sclera were placed into a fixative solution that contained anhydrous acetic acid/95\% ethanol/ $40 \%$ formalin/distilled water at 1:15:6:30. All through the experiment, tissues were passed individually from one reagent to another. After 60 minutes of fixation, the choroid was detached from the underlying sclera, washed in $95 \%$ ethanol, and stained for 40 minutes in $0.25 \%$ solution of toluidine blue in $70 \%$ ethanol acidified with hydrogen chloride ( $\mathrm{pH}$ 2.4). Choroids were dehydrated, folds were removed under the stereomicroscope, and choroids were mounted in Eukitt (VWR). Under these staining conditions, only mast cell granules were stained.

\section{Choroidal Mast Cell Quantification}

Choroidal mast cells were then counted with an ocular grid at the magnification of $\times 250 ; 200$ to 1000 mast cells were assessed on 10 to 20 grid areas for each choroid. Mast cells were considered as degranulated when showing an irregular shape, altered cell membrane, and extracellular granules.

The density of degranulated cells (means \pm SEM cells per $\mathrm{mm}^{2}$ of choroid) were calculated at different time intervals after injection in compound 48/80-injected eyes and in contralateral noninjected eyes.

\section{Immunohistochemistry on Flat Mounts of RPE/Choroid}

Enucleated eyes were fixed in $4 \%$ paraformaldehyde for 15 minutes at room temperature and sectioned at the limbus; the anterior segment and the retina were discarded. Flat mounts of RPE/choroids were fixed for an additional 15 minutes in 
acetone at $-20^{\circ} \mathrm{C}$. Specimens were incubated overnight at $4^{\circ} \mathrm{C}$ with primary antibody diluted in phosphate-buffered saline and $0.1 \%$ Triton X-100. Primary antibody used was rabbit polyclonal anti-occludin (dilution 1: 200; Zymed, San Francisco, CA). Occludin is an integral plasma-membrane protein located at the tight junctions and is involved in cell adhesion and permeability. ${ }^{33}$ The corresponding Alexa secondary antibody (Invitrogen Life Technology, Carlsbad, CA) was used to reveal the primary antibody, and sections were counterstained with DAPI (Sigma-Aldrich). Sections and flat mounts were viewed with a fluorescence microscope (Olympus BX51; Olympus, Tokyo, Japan) and confocal microscope (LSM 510 laser scanning microscope Zeiss; Carl Zeiss, Le Pecq, France). Images were exported to Photoshop
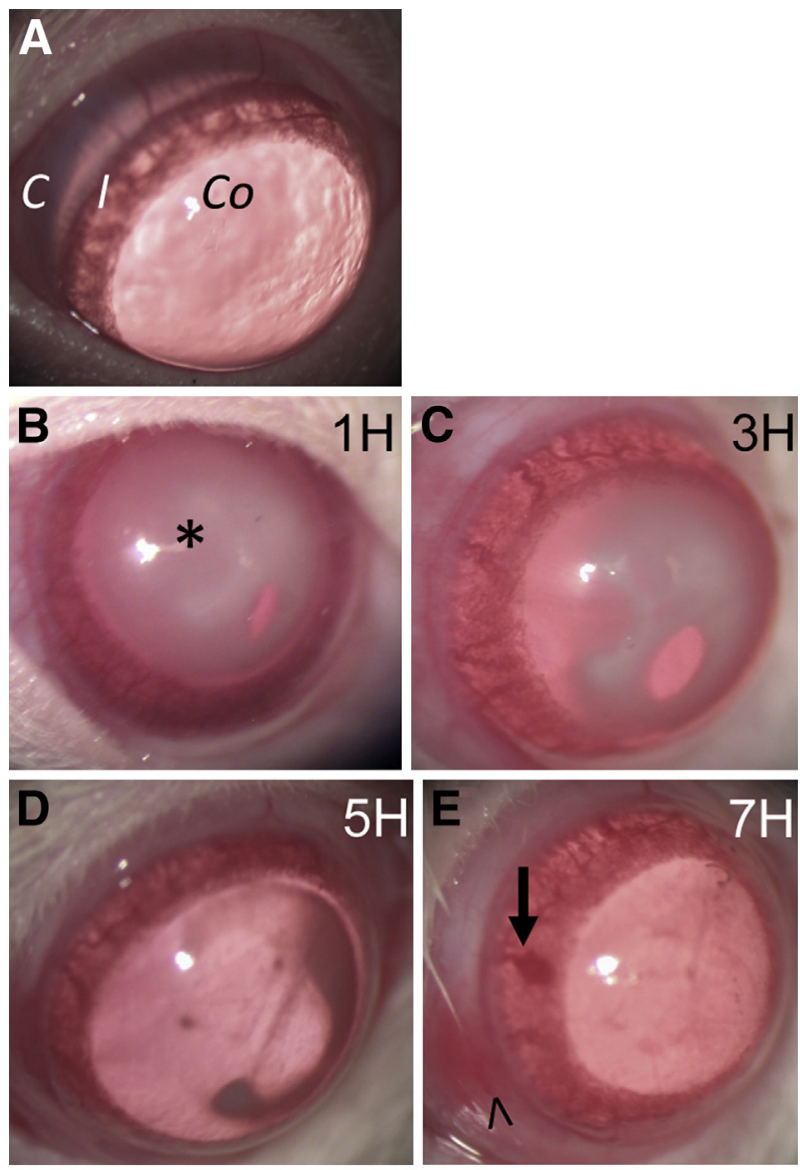

$\mathbf{F}$

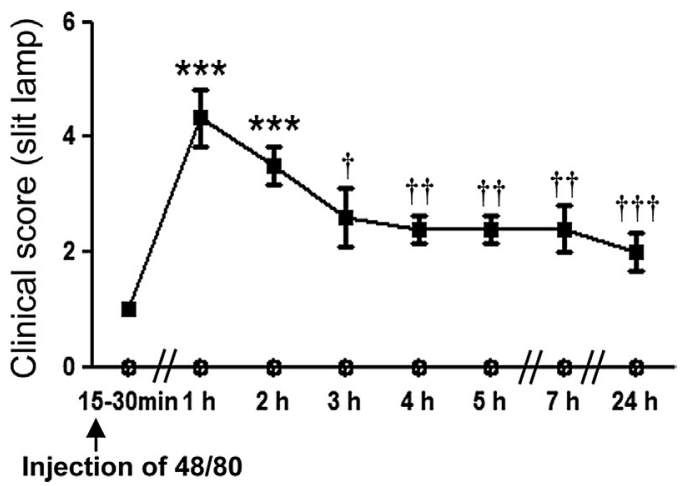

CS5 software version 12 (Adobe Systems, Mountain View, CA) for preparation of final images. Staining that omitted the primary antibody served as negative control.

\section{Histologic Sections for the Assessment of Ocular Disorders and Choroidal Thickness}

Eyes were fixed in $0.5 \%$ glutaraldehyde $/ 4 \%$ paraformaldehyde for 2 hours, dehydrated in a graded alcohol series $(50 \%, 70 \%$, $95 \%$, and $100 \%$ ), and embedded in epoxy resin; 5- $\mu \mathrm{m}$ section were cut and stained with toluidine blue. The structural characteristics and abnormal modifications of ocular tissues were examined under a light microscope (DM5500B; Leica, Nanterre, France).

Choroidal thickness was measured (ImageJ version 1.43u; $\mathrm{NIH}$, Bethesda, MD; http://imagej.nih.gov/ij) on photographs taken on historesin sections from the optic nerve to the ciliary body. Each measurement was taken at $300 \mu \mathrm{m}$ on each side of the optic nerve ${ }^{34}$ of compound 48/80-injected eyes, contralateral noninjected eyes, and sodium chloride-injected eyes.

\section{TUNEL Assay}

Enucleated eyes were snap-frozen in Tissue-Tek OCTcompound (Bayer Diagnostics, Puteaux, France). Cryostat sections $(10 \mu \mathrm{m})$ were fixed in $4 \%$ paraformaldehyde for 15 minutes and permeabilized with $0.1 \%$ Triton X-100 for 30 minutes. Apoptosis of cells was assessed on cryostat sections with a terminal deoxynucleotidyl transferase dUTP nick-end labeling (TUNEL) kit (Roche, Indianapolis, IN) in strict accordance with the manufacturer's instructions.

Cytokine and Chemokine Analysis in Ocular Fluids by Multiplex Enzyme-Linked Immunosorbent Assay

Aqueous humor and vitreous body (ocular media) from each eye were collected and pooled. A sample of 15 to $25 \mu \mathrm{L}$ of

\footnotetext{
Figure 1 Clinical examination and grading of the abnormal signs in the anterior segment of the eye after subconjunctival injection of compound 48/80. A-E: Slit lamp photographs were obtained from rats not injected (A) and rats injected in the conjunctiva with compound 48/80 (B-E). The eyes were observed from 3 to 7 hours after injection. A cataract was observed in 17 of 25 eyes (68\%), from 3 hours (B, asterisk) to diminish progressively up to 7 hours. At 7 hours in this eye, hemorrhages were observed in the iris (E, arrow) and in the conjunctiva (E, caret). F: Graph shows the clinical grading of rats injected with compound 48/80 in the conjunctiva of right eyes (closed squares) and in the noninjected contralateral left eyes (open squares) and observed with the slit lamp from 15 to 30 minutes to 24 hours. Noninjected left eyes did not show any clinical abnormalities. In the compound 48/80-injected right eyes, clinical signs developed from 15 to 30 minutes and significantly increased and peaked at 1 to 2 hours. Clinical signs significantly decrease at 3, 4, 5, 7, and 24 hours compared with peak amounts found at 1 to 2 hours. $n=7$ rats injected with compound $48 / 80(\mathbf{A}-\mathbf{E}) ; n=25$ rats injected with compound $48 / 80$ for observation of cataract $(\mathbf{A}-\mathbf{E}) ; n=6$ compound $48 / 80$-injected eyes $(\mathbf{F}) ; n=6$ contralateral non-injected eyes $(\mathbf{F}) .{ }^{* * *} P<0.001$ compared with 15 to 30 minutes; ${ }^{\dagger} P<0.05,{ }^{\dagger \dagger} P<0.01$, and ${ }^{\dagger \dagger \dagger} P<0.001$ compared with 1 hour. Original magnification: $\times 7(\mathbf{A}-\mathbf{E})$. C, conjunctiva; Co, cornea; I, iris.
} 
ocular media from each eye was obtained and centrifuged to allow separation of ocular fluids from ocular infiltrating cells. Sodium chloride-injected eyes served as control. According to the manufacturer's instructions, multiplex enzyme-linked immunosorbent assay (Milliplex Map Kit, Saint-Quentin en Yvelines, France) was performed on rat ocular fluids (xMAP technology assay) with measurement of the following inflammatory mediators: chemokines [monocyte chemoattractant protein-1/chemokine ligand 2 (CCL2), macrophage inflammatory protein $1-\alpha / C C L 3$, regulated on activation of normal $\mathrm{T}$ cell expressed and secreted/CCL5, interferon- $\gamma$-inducible protein 10/CXCL10, and growthrelated oncogene/keratinocyte-derived cytokine/CXCL1/ cytokine-induced neutrophil chemoattractant] and inflammatory mediators [IL-1 $\beta$, IL-18, TNF- $\alpha$, IL-2, interferon- $\gamma$, IL-4, IL-5, IL-6, IL-10, IL-13, IL-17, and vascular endothelial growth factor (VEGF); Clinisciences, Montrouge, France]. Detection thresholds were estimated at approximately 1 to $10 \mathrm{pg} / \mathrm{mL}$. The nomenclature CCL2 and CXCL1 was used throughout the study.

\section{Statistical Analysis}

Data are expressed as means \pm SD. Statistical analysis was performed with the Graphpad Prism5 program (Graphpad Software, San Diego, CA). A Mann-Whitney test was used for comparison between two groups, and comparisons with more than two groups were performed with one-way analysis of variance test, followed by Bonferroni comparison; significance was investigated at the 5\% level for all test types.

\section{Results}

\section{Subconjunctival Injection of Compound 48/80 Induces Clinical Ocular Inflammation}

Biomicroscope (slit lamp) examination was performed at different time intervals after compound 48/80 or sodium chloride injection. Unilateral clinical signs of ocular inflammation were observed (Figure 1). From 3 to 24 hours, hazy cornea, fibrin deposit, hypopion (small amount of pus or collection of white cells), and synechiae (adherence of the iris to the lens) were observed in the anterior chamber of the eyes. Punctate hemorrhages in the iris were occasionally found (Figure 1E). In 17 of 25 rats (68\%) a transitory cataract was observed from 1 hour after compound 48/80 injection that persisted until the third to sixth hours and then faded (Figure 1, B-D). No clinical sign of inflammation could be observed in contralateral noninjected eyes (Figure 1A) and in rats injected with sodium chloride (not shown).

Although no abnormal signs were detected in the left eyes not injected with compound 48/80, all right eyes injected with compound 48/80 showed significant signs of anterior segment inflammation from 15 to 30 minutes, reaching a peak at 1 to 2 hours, and significantly slowing, decreasing between 3 and 24 hours after injection (Figure 1F).
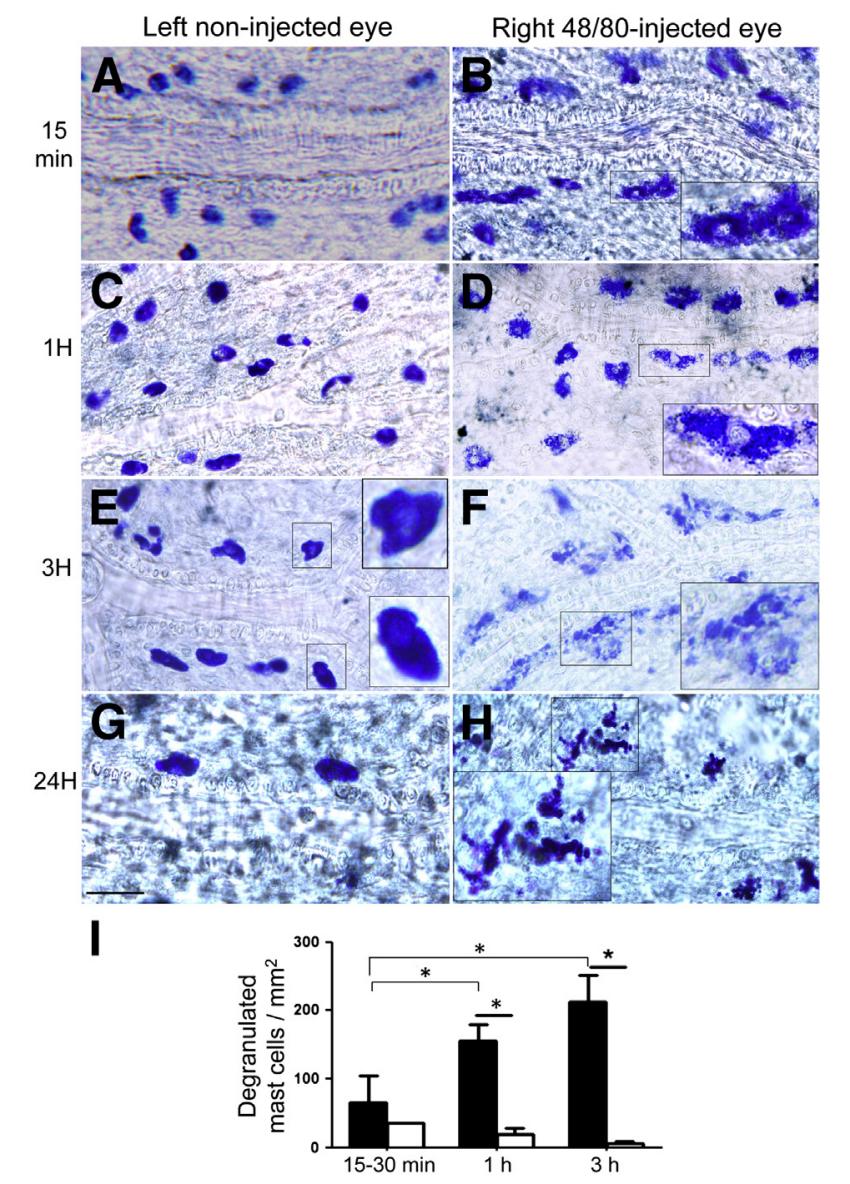

Figure 2 A-H: Structural characteristic alterations of mast cells in flat mounts of the choroid at different time points after subconjunctival injection of compound 48/80. At all time intervals in the left noninjected eye (A, C, E, and G; inset, E), numerous normal mast cells were detected along choroidal vessels. In contrast, in the right compound 48/80-injected eyes, mast degranulation was visible at all time intervals tested as mast cell granules dispersed in the surrounding tissue (B, D, F, and $\mathbf{H}$; insets, $\mathbf{B}, \mathbf{D}, \mathbf{F}$, and $\mathbf{H})$. At 15 minutes, occasional degranulated mast cells were seen (inset, $\mathbf{B}$ ), more numerous at 1 hour with granules extruded from the cytoplasm (inset, D). At 3 hours, an extensive and massive degranulation with reduced density of cytoplasmic granules was detected in all mast cells present in the choroid (inset, F). At 24 hours, all mast cells presented an abnormal shape with granules again stained intensively in blue with toluidine blue (inset, H). Photomicrographs were obtained from one eye per time point and are representative of similar flat mounts stained from three rats per time point. I: Choroidal mast cells density was calculated on flat mounted preparations. The number of degranulated mast cells was significantly higher at 1 hour and 3 hours in compound 48/80-injected eyes $(P<0.05$; black bars) compared with contralateral noninjected eyes (white bars). Compared with the number of degranulated mast cells at 15 to 30 minutes, the number of degranulated mast cells was significantly higher $(P<0.05)$ at 1 hour and 3 hours. The difference between the numbers of degranulated mast cells at 1 hour compared with 3 hours was not significant. Low number of degranulated mast cells was detected at all time points in noninjected eyes. Data are expressed as means \pm SEM. $n=3$ rats per condition; ${ }^{*} P<0.05$. Scale bar: $30 \mu \mathrm{m}(\mathbf{A}-\mathbf{H})$. Original magnification: $\times 40$ (main images); $\times 2$ (insets, $B, F$, and $H$ ); $\times 3$ (insets, $\mathbf{D}$ and $\mathrm{E}$ ).

\section{Modifications of Structural Characteristics and Quantification of Mast Cells in Choroid Flat Mounts}

The structural characteristics of choroidal mast cells was analyzed with flat mount preparations (Figure 2). Mast cells 


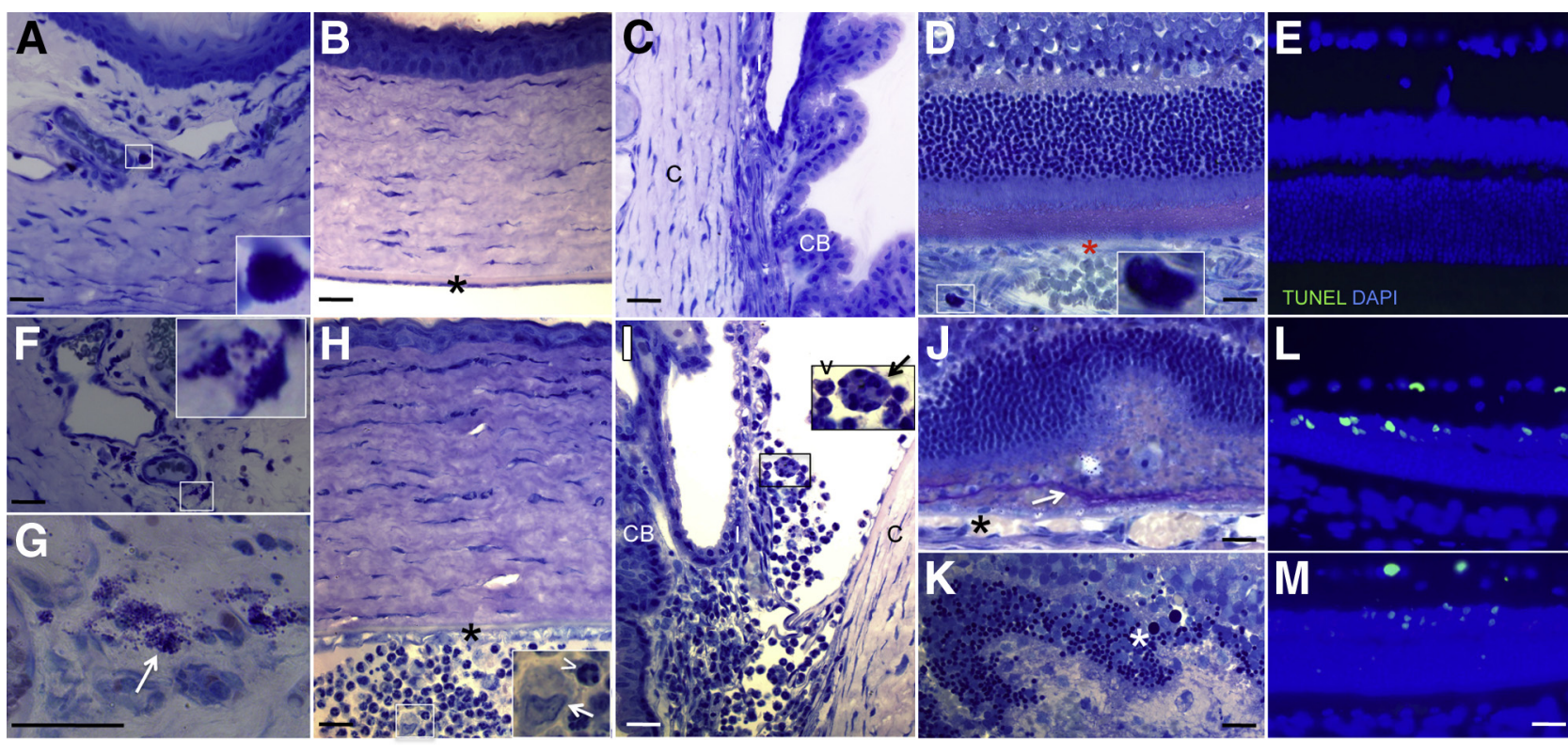

Figure 3 Abnormal effects of mast cell degranulation in ocular tissues with TUNEL assay. Historesin sections of left noninjected eyes (A-D) and right compound 48/80-injected eyes (F-K) between 1 hour and 24 hours after compound 48/80 injection. In the left noninjected eyes (A and $\mathbf{D})$ normal mast cells (insets) were observed in the vicinity of vessels at the limbus of the cornea (A) and near choroidal vessels (D). Normal aspect of the ocular structures: cornea with endothelial cells regularly distributed (B, asterisk), normal iris and ciliary body (C), retina (D), and choriocapillaris (D, asterisk). In contrast, in the right compound 48/80-injected eyes (F-K), at 1 hour to 3 hours, degranulated mast cells were observed in the vicinity of ocular vessels at the limbus of the cornea (inset, $\mathbf{F}$ ), in the conjunctiva (G, arrow). From 1 hour to 3 hours to persist up to 24 hours after compound 48/80 injection, an important infiltration of PMN cells (insets, $\mathbf{H}$ and $\mathbf{I}$, carets) and macrophages (insets, $\mathbf{H}$ and $\mathbf{I}$, arrows) was observed in the aqueous humor behind the vacuolated endothelium of the cornea ( $\mathbf{H}$, asterisk) and in the anterior chamber angle (I). Important dilation of the choriocapillaris was observed (J, asterisk) associated with focal retinal detachment (J). Starting at 1 hour $(\mathbf{J})$ after compound 48/80 injection to be important at 3 to 24 hours (K), alterations of the retinal nuclear cell layers with picnotic aspects of the nuclei were visible at the level of the retinal detachment (K, asterisk). Fibrin deposits were seen all along the RPE (J, arrow). At 24 hours, large retinal tissue destruction was observed (K). Retinal sections were immunostained by TUNEL assay (green) and DAPI (blue) (E, L, and M). Normal retina was observed in the left noninjected eye $(\mathbf{E})$. In contrast apoptotic retinal cells (TUNEL ${ }^{+}$nuclei) were detected in the three nuclear cell layers of the retina at 3 hours after compound 48/80 injection (L) and at 24 hours (M) that further led to the extensive lesions of retinal cells shown in historesin section (K, asterisk). $n=3$ compound 48/80-injected eyes; $n=3$ contralateral noninjected eyes. Scale bars: $30 \mu \mathrm{m}$ (A-M). Original magnification: $\times 40$ (main images, $\mathbf{A}-\mathbf{F}$ and $\mathbf{H}-\mathbf{M}) ; \times 60(\mathbf{G}) ; \times 4$ (insets). C, cornea; $\mathrm{CB}$, ciliary body; I, iris; PMN, polymorphonuclear.

are regularly located around large choroidal vessels. In left noninjected eyes (Figure 2, A, C, E, and G) and sodium chloride-injected eyes (not shown), mast cells displayed an intact structural characteristics at all time points with a high number of condensed intracellular granules intensively stained with toluidine blue in the cytoplasm. In contrast, as early as 15 to 30 minutes after compound $48 / 80$ injection occasional degranulated mast cells were seen (Figure 2B). At 1 hour after compound 48/80 injection, the number of degranulated mast cells significantly increased compared with 15 to 30 minutes $(P<0.05)$ (Figure $2 \mathrm{I})$ with granules extruded from the cytoplasm (Figure 2D). At 3 hours, mast cells showed reduced density of cytoplasmic granules and an extensive and massive degranulation in all mast cells present in the choroid (Figure 2F). At 24 hours, all mast cell still presented an abnormal shape, but the granules were again stained intensively (Figure $2 \mathrm{H}$ ).

Choroidal mast cell density was calculated on flatmounted preparations. Variations in the number of degranulated choroidal mast cells at 15 to 30 minutes, 1 hour, and 3 hours are shown in Figure 2I. Compared with contralateral noninjected eyes, the number of degranulated mast cells was significantly higher at 1 hour and 3 hours in compound 48/80-injected eyes $(P<0.05)$ (Figure 2I). Further, compared with the number of degranulated mast cells at 15 to 30 minutes, the number of degranulated mast cells was significantly increased $(P<0.05)$ at 1 hour and 3 hours. But no substantial difference was observed between the number of degranulated mast cells at 1 hour compared with 3 hours.

\section{Ocular Disease Induced by Mast Cell Degranulation}

Abnormal modifications of ocular tissues were evaluated in historesin sections. In left noninjected eyes, mast cells showed a normal resting shape (Figure 3, A and D), at the vicinity of vessels at the limbus of the cornea (Figure 3A) and also in the choroid (Figure 3D). In the right compound 48/80-injected eyes, degranulated mast cells were observed in the vicinity of vessels at the limbus of the cornea (Figure $3 \mathrm{~F}$ ) and in the conjunctiva (Figure 3G). In these eyes, mast cell degranulation in the anterior segment was associated with intense infiltration of polymorphonuclear cells (Figure 3H) and macrophages (Figure $3 \mathrm{H}$ ) in the anterior chamber at 3 hours to persist up to 24 hours and 


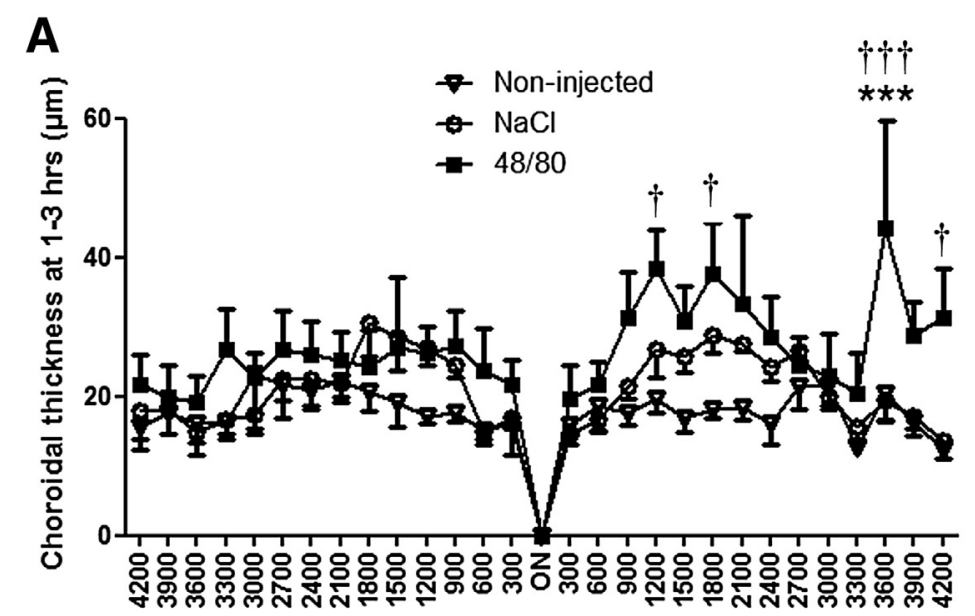

B

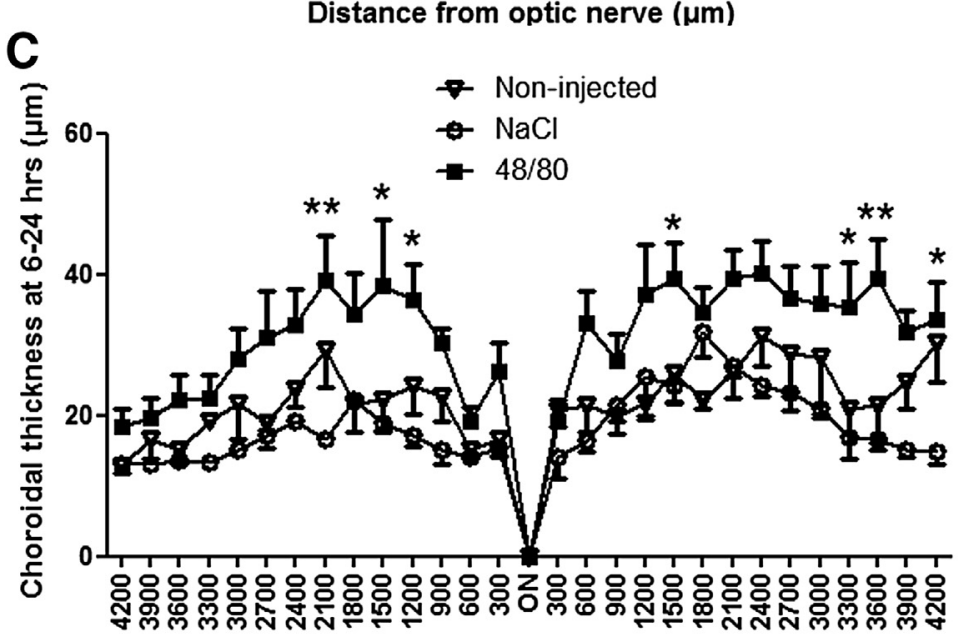

D
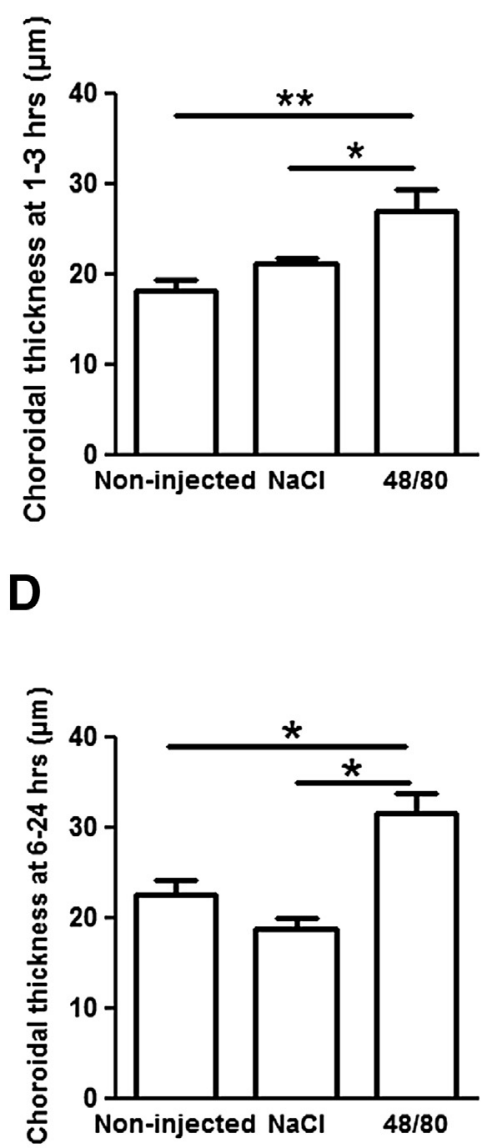

Distance from optic nerve $(\mu \mathrm{m})$

Figure 4 Effect of subconjunctival injection of compound 48/80 on choroidal thickness. Choroidal thickness was measured on photographs taken on historesin sections from the optic nerve to the ciliary body. A and B: At 1 hour and 3 hours after injection of compound 48/80, choroids from eyes injected with compound 48/80 show a localized significant increase of thickness compared with contralateral eyes and sodium chloride-injected eyes. C and D: At 6 and 24 hours, choroids from rats injected with compound 48/80 show a significant and extended increase of choroidal thickness compared with sodium chloride-injected eyes. $n=6$, compound 48/80-injected eyes at 1 to 3 hours; $n=6$, contralateral noninjected eyes at 1 hour to 3 hours; $n=5$, sodium chloride-injected eyes at 1 hour to 3 hours; $n=6$, compound 48/80-injected eyes at 6 to 24 hours; $n=6$, contralateral noninjected eyes at 6 to 24 hours; $n=6$, sodium chloride-injected eyes at 6 to 24 hours. ${ }^{*} P<0.05$, ${ }^{*} P<0.01$, and ${ }^{*} * * P<0.001$ compound $48 / 80$-injected eyes versus sodium chlorideinjected eyes; ${ }^{\dagger} P<0.05,{ }^{\dagger \dagger} P<0.001$ compound $48 / 80$-injected eyes versus with noninjected eyes.

with alterations of corneal endothelial cells (Figure 3H) compared with normal corneal endothelium in noninjected eye (Figure 3B). In the anterior chamber angle and trabecular meshwork near the iris and ciliary body compared to the normal iris and ciliary body in noninjected eye (Figure 3C), infiltration of polymorphonuclear cells and large macrophages (Figure 3I) were visible. In the posterior segment, mast cell degranulation was associated with fibrin exudate above the RPE in the subretinal space (Figure 3J) together with choroidal vessel dilation (Figure 3J). Moreover, exudative retinal detachments appeared in the same locations as moderate-to-extensive ruptures of the RPE barrier and important retinal folds (Figure 3, J and K).

Starting at 1 hour (Figure $3 \mathrm{~J}$ ) after compound 48/80 injection to be important at 3 to 24 hours (Figure $3 \mathrm{~K}$ ), alterations of the retinal nuclear cell layers with picnotic aspects of the nuclei of photoreceptors and bipolar cells were visible at the level of the retinal detachment. At 24 hours, detachments and large destructions of the retina were observed (Figure 3K). Compared to normal retina in the left noninjected eye (Figure $3 \mathrm{E})$, numerous $\mathrm{TUNEL}^{+}$nuclei were detected at 3 hours (Figure 3L) and at 24 hours (Figure 3M), in the three nuclear cell layers, aspects consistent with the abnormal aspect of retinal cells observed in historesin section (Figure 3K).

\section{Increase of Choroidal Thickness in Compound 48/80-Injected Eyes}

At 1 hour to 3 hours, compared with choroidal thickness in the left noninjected eyes and in $\mathrm{NaCl}$-injected eyes, a 


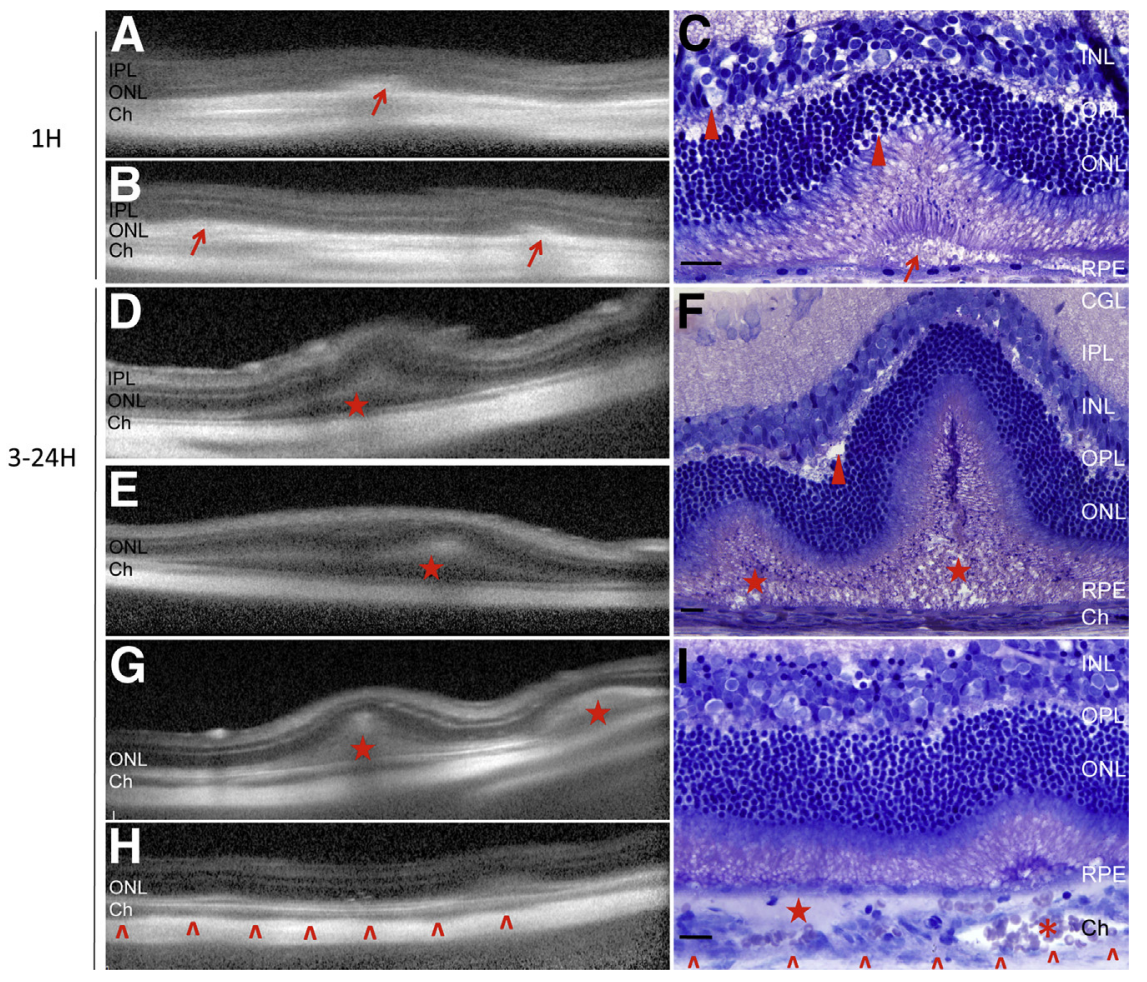

Figure 5 Serous retinal detachment after subconjunctival injection of compound 48/80. OCT (A, $\mathbf{B}, \mathbf{D}, \mathbf{E}, \mathbf{G}$, and $\mathbf{H})$ and corresponding historesin sections $(\mathbf{C}, \mathbf{F}$, and $\mathbf{I})$ at different time points after compound 48/80 injection. At 1 hour, undulations and hyperreflective areas were detected at the level of RPE (A and $\mathbf{B}$, arrows) corresponding to small retinal detachments on histologic sections (C, arrow). From 3 to 24 hours after injection of compound $48 / 80$, retinal serous detachments were observed all around the retinal surface with presence of subretinal fluid (D-G, stars). Edematous areas were detected in the retina ( $\mathbf{C}$ and $\mathbf{F}$, arrowheads). An important dilation was detected in the choriocapillaries (I, star) and choroidal vessels (I, asterisk), which was confirmed by choroidal thickness measurement ( $\mathbf{H}$; see also Figure 4$)$. The carets in $\mathbf{H}$ and $\mathbf{I}$ represent the junction between the choroid and the sclera (lamina fusca). The presence of ocular inflammation and cataract altered the resolution of OCT images. $n=6$ compound 48/80-injected eyes at 1 hour; $n=6$ compound 48/80-injected eyes at 3 to 6 hours. Scale bars: $25 \mu \mathrm{m}(\mathbf{C}, \mathbf{F}$, and I). Ch, choroid; GCL, ganglion cell layer; INL, inner nuclear layer; IPL, inner plexiform layer; $\mathrm{OCT}$, optical coherence tomography; $\mathrm{ONL}$, outer nuclear layer; $\mathrm{OPL}$, outer plexiform layer; RPE, retinal pigmented epithelium.

significant and localized increase of choroidal thickness in one-half of the choroidal surface was detected in right compound 48/80-injected eyes, probably corresponding to the site of injection of compound $48 / 80$ in the conjunctiva (Figure 4, A and B). At 6 to 24 hours, the choroidal thickness increase extended also to the periphery and all over the choroid surface (Figure 4, C and D).

\section{OCT Examination of Posterior Segment of the Eye}

One hour after compound 48/80 injection, the choroid/RPE presented undulations, the apex of which were hyperreflective (Figure 5, A and B). From 3 to 24 hours after compound 48/80 subconjunctival injection, larger and multiple SRDs were observed with pockets of subretinal fluid (Figure 5, D-G). Detachments of the neuroretina, because of subretinal accumulation of material, were observed on histologic section (Figure 5C). Edema was located in the retinal nuclear cell layers (Figure 5, C and F). An increase of the choroidal thickness (Figure 5, H and I) was observed related to dilation of the choriocapillaris (Figure 5I) and large choroidal vessels (Figure 5I) and was confirmed by choroidal thickness measurements on historesin sections (Figure 4). No abnormal changes were observed in contralateral noninjected eyes.

\section{Effect of Subconjunctival Injection of DSCG on SRD on OCT and Histologic Analysis}

The inhibitor of mast cell mediator release, DSCG, was injected subconjunctivally in the right eye at the nasal site 15 minutes before compound $48 / 80$ at the temporal site. Control rats received $\mathrm{NaCl} 0.9 \%$ before compound 48/80. Rats injected with sodium chloride + compound 48/80 developed SRDs, starting 15 to 30 minutes after compound 48/80 injection to increase at 1 to 2 hours and reach a maximum at 3 to 4 hours in $80 \%$ of cases and decline at 6 to 7 hours, the retina being flattened at 24 hours in all eyes examined (Table 1 ). In contrast, rats injected with DSCG + compound 48/80 showed limited SRDs in $16.7 \%$ of cases, starting 3 to 4 hours after compound 48/80 injection, to persist at 6 to 7 hours and resolve at 24 hours. No clinical signs of retinal detachment could be observed in the contralateral noninjected eyes. The injection of DSCG was then effective to block SRDs $(P<0.05)$.

Interestingly, OCT performed 1 month after injection of sodium chloride + compound $48 / 80$ or DSCG + compound $48 / 80$ did not show any relapse of the disease and showed a dystrophic retina at places where retinal detachments occurred at 3 or 4 hours. Histologic examination of the eyes confirmed that DSCG protected against lesions induced by compound $48 / 80$ in $83.3 \%$ of rats (Figure 6, A and B), whereas only 1 of 6 rats $(16.7 \%)$, developed histologic lesions (Figure 6, C and D).

\section{RPE Barrier Breakdown Induced by Mast Cell Degranulation}

RPE flat mounts were used to visualize the RPE cell junctions at 1 hour after compound 48/80 injection. In sodium chloride and contralateral noninjected eyes, occludin labeled a regular 
Table 1 Serous Retinal Detachment in Rats Treated with Subconjunctival DSCG versus Sodium Chloride before Compound 48/80 Subconjunctival Injection followed by Optical Coherence Tomography

\begin{tabular}{|c|c|c|}
\hline \multirow[b]{2}{*}{$\begin{array}{l}\text { Time after } \\
\text { compound } \\
48 / 80 \text { injection }\end{array}$} & \multicolumn{2}{|l|}{ Treatment } \\
\hline & $\begin{array}{l}\mathrm{NaCl}+\text { compound } \\
48 / 80, \text { number of } \\
\text { positive eyes/total }(\%)\end{array}$ & $\begin{array}{l}\text { DSCG + compound } \\
48 / 80, \text { number of } \\
\text { positive eyes/total }(\%)\end{array}$ \\
\hline $15-30$ minutes & $2 / 10(20)$ & $0 / 6(0)$ \\
\hline $1-2$ hours & $4 / 10(40)$ & $0 / 6(0)$ \\
\hline $3-4$ hours & $8 / 10(80)$ & $1 / 6^{*}(16.7)$ \\
\hline $6-7$ hours & $6 / 10(60)$ & $1 / 6(16.7)$ \\
\hline 24 hours & $0 / 10(0)$ & $0 / 6(0)$ \\
\hline $\begin{array}{l}\text { Number of } \\
\text { SRD/total (\%) }\end{array}$ & $8 / 10(80)$ & $1 / 6^{*}(16.7)$ \\
\hline
\end{tabular}

DSCG or sodium chloride was injected 15 minutes before compound 48/80 administration. $n=10$ rats in $\mathrm{NaCl}+$ compound 48/80 group; $n=$ 6 rats in DSCG + compound $48 / 80$ group.

${ }^{*} P<0.05$.

DSCG, disodium cromoglycate.

hexagonal membrane of the RPE cells (Figure 7A). In compound 48/80-injected eyes, an abnormal shape in some RPE cells with irregular occludin labeling was observed (Figure 7B). In particular RPE cell defects (Figure 7, B and C) and localized enlargement of intercellular space (Figure 7D) were present throughout.

Close examination of historesin sections showed a regular interface between the RPE cell monolayer and Bruch membrane in contralateral noninjected eyes (Figure 7E), whereas in compound 48/80-injected eyes large alterations of the RPE were detected at all time points, in locations adjacent to the choriocapillaris (Figure 7F). RPE cells were detached from the basal membrane as large sheets of RPE in the subretinal space (Figure 7G). These round, binuclearly detached cells allowed the positive identification of the RPE cells. ${ }^{35}$

Effect of Mast Cell Degranulation by Compound 48/80 on Ocular Cytokine and Chemokine Concentrations in Ocular Fluids

Multiplex enzyme-linked immunosorbent assay showed that the amount of several inflammatory mediators was significantly higher in compound 48/80-injected eyes than in control sodium chloride-injected eyes (Figure 8). As early as 1 hour after compound 48/80 injection, TNF- $\alpha$ was significantly increased compared with sodium chloride-injected eyes (Figure 8A). This increase persisted at 3 hours but not at 6 hours. A significantly increased concentration of IL-5 was observed at 3,6, and 24 hours (Figure 8B), together with significantly increased concentrations of IL- 6 and CCL2 at 6 and 24 hours (Figure 8, C and D). Furthermore a significant increase of IL-1 $\beta$, CXCL-1, and IL-18 was observed at 24 hours (Figure 8, E-G), whereas significant decrease of VEGF occurred at this time (Figure 8I). Concentrations of IL-18 (Figure 8H) and VEGF (Figure 8J) mirrored each other, suggesting co-regulation. The cytokine concentrations in the contralateral noninjected eyes were consistent with concentrations found in sodium chloride-injected eyes.

\section{Discussion}

A local subconjunctival injection of compound $48 / 80$ (which specifically induces mast cell degranulation) was used to analyze the sequence of events occurring in the eye after mast cell degranulation. It showed a strong clinical and structural characteristic inflammatory reaction detected in both posterior and the anterior segments of the eye. In this study a high dose of compound 48/80 was injected, inducing an acute form of ocular inflammation as shown by infiltration of neutrophils and macrophages in both segments of the eye. The acute mast cell degranulation in ocular tissues also induced remarkable posterior segment abnormalities, beginning with choroidal thickening and outer retinal barrier breakdown that resulted in SRDs. Interestingly, the subconjunctival injection of the inhibitor of mast cell mediator release, DSCG, before compound 48/80 injection diminished SRDs and histologic retinal lesions. This further demonstrates the key role of mast cell degranulation in the abnormal manifestations induced by compound $48 / 80$ injection.

Interestingly, SRDs are observed in some forms of acute posterior uveitis such as Vogt-Koyanagi-Harada ${ }^{24}$ disease, suggesting that these eyes may share some pathogenic mechanisms.

Because mast cells mature locally in the vicinity of vascularized tissues, the site of their final residence, ${ }^{6}$ a local

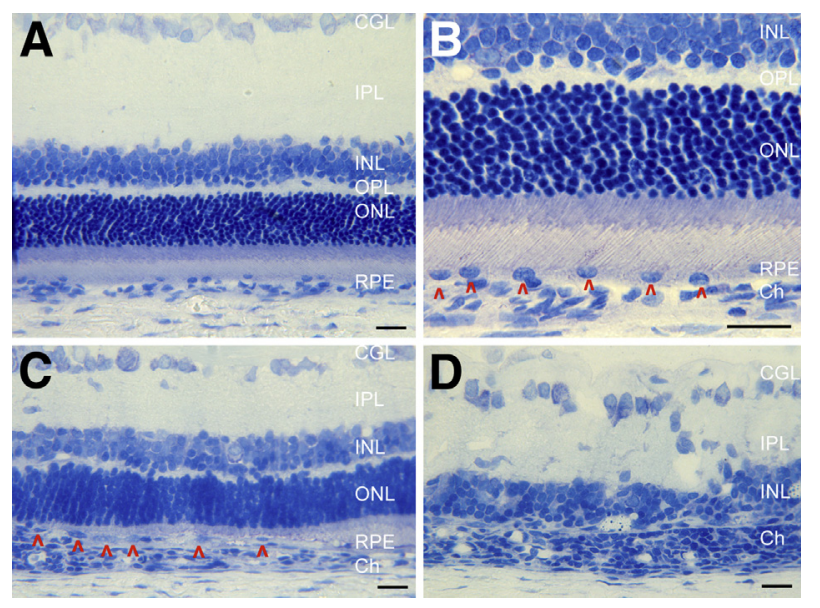

Figure 6 Historesin sections 1 month after compound 48/80 + DSCG subconjunctival injection. A and B: No histologic lesions were detected in $83.3 \%$ of rats treated with DSCG with a normal retina aspect (A) and RPE cells (B, carets) regularly distributed between the photoreceptor cells and the choroid (B). C and D: Different retinal lesions were observed only in one treated rat of six rats $(16.7 \%)$. A preserved retinal tissue was detected, and RPE cells seemed to be detached from Bruch membrane (C, carets). In the same eye, localized and total destruction of photoreceptor and RPE cells was also observed (D). $n=6$ rats. Scale bars: $30 \mu \mathrm{m}$. Ch, choroid; DSCG, disodium cromoglycate; $\mathrm{GCL}$, ganglion cell layer; INL, inner nuclear layer; IPL, inner plexiform layer; $0 N L$, outer nuclear layer; OPL, outer plexiform layer; RPE, retinal pigmented epithelium. 

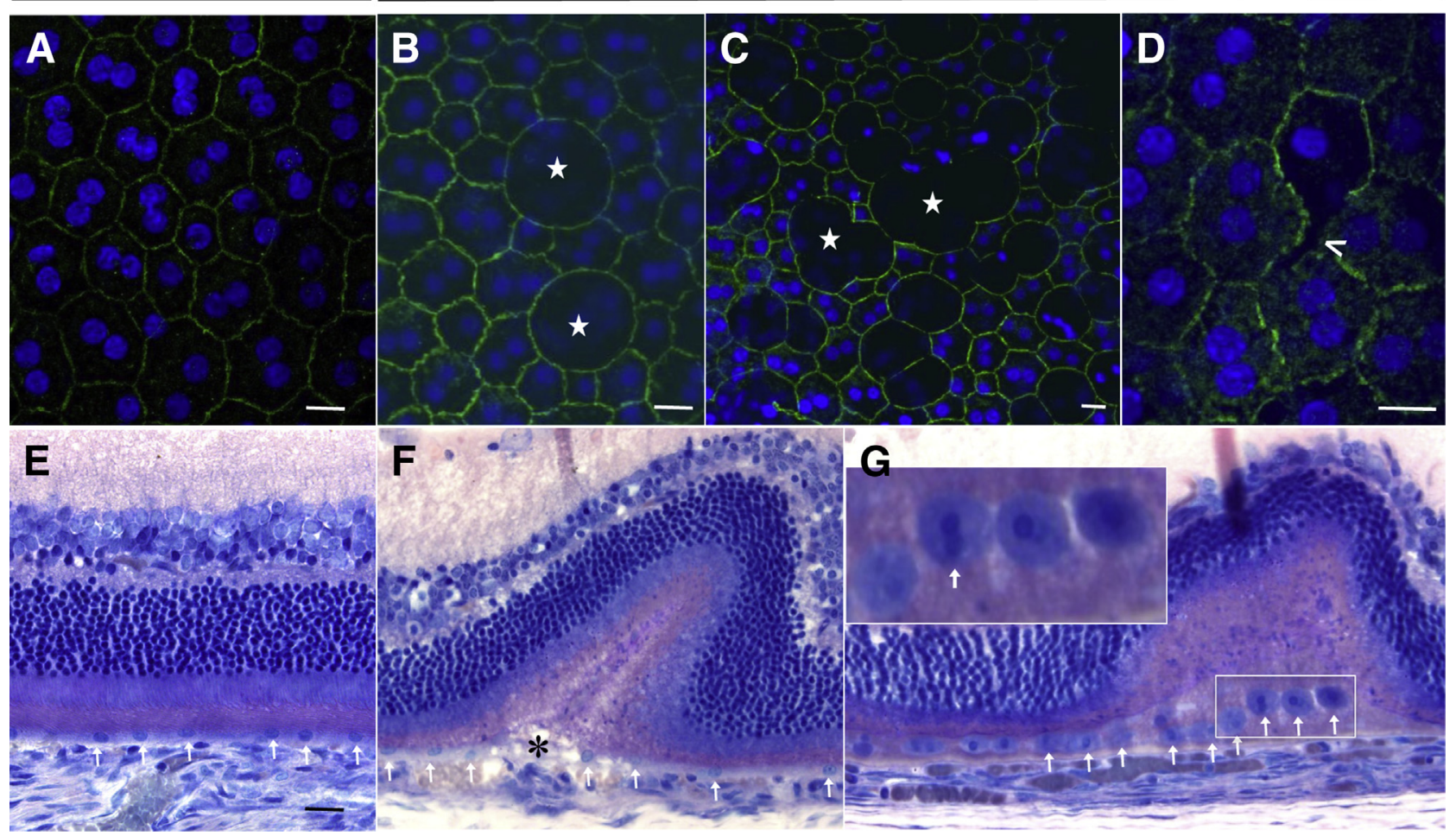

Figure 7 Effects of mast degranulation on RPE cell junctions by subconjunctival injection of compound 48/80. A-D: RPE flat mounts immunostained with occludin (green) and DAPI (blue) after injection of compound $48 / 80$ or sodium chloride. In sodium chloride controls, occludin labeled the regular hexagonal membrane of RPE cells (A), whereas 1 hour after injection of compound 48/80 enlarged RPE cells were seen (B and C, stars) with irregular occludin labeling originating from loss of junctions between some RPE cells (D, caret). E-G: On corresponding historesin sections, in controls, RPE cells are regularly distributed between the photoreceptor cells and the choroid (E, arrows). In contrast, after injection of compound 48/80, whereas RPE cells are still regularly distributed (arrows), some RPE cells are altered or missing (F, asterisk). In some wide places, RPE cells are separated from one to another, show a round shape, and are detached from the basal membrane (G, arrows; inset, G) in front of a retinal detachment area. Binuclearly detached cell (inset, G, arrow) allowed the identification of the RPE cells. Photomicrographs are representative of similar sections stained from rats injected with compound 48/80 and rats injected with sodium chloride per each time point. $n=6$, compound 48/80-injected eyes (A-D); $n=5$, sodium chloride-injected eyes $(\mathbf{A}-\mathbf{D}) ; n=3$, rats injected with compound 48/80 (E-G); $n=3$, rats injected with sodium chloride. Scale bars: $25 \mu \mathrm{m}(\mathbf{A}-\mathbf{E})$. Original magnification: $\times 40(\mathbf{A}, \mathbf{B}$, and $\mathbf{E}-\mathbf{G}) ; \times 20(\mathbf{C}) ; \times 60(\mathbf{D})$; $\times 4$ (insets). RPE, retinal pigmented epithelium.

degranulation of mast cell in one eye is not expected to induce disease in the contralateral eye, which was confirmed by unilateral clinical signs and the lack of structural characteristic changes in the contralateral eye. Interestingly, a second subconjunctival injection of compound $48 / 80$ performed 7 days after the first injection induced the same abnormal signs (not shown). In human pathology, one could expect that, if the stimulus persists, successive degranulation could occur, leading to chronic signs.

In compound 48/80-injected eyes, mast cell degranulation elicited a complex sequence of structural characteristic changes. The early blood-aqueous barrier breakdown coincided with a transitory cataract, which dissipated spontaneously by 6 hours after compound 48/80 injection. Such transitory cataract was not observed in other acute models of intraocular inflammation, suggesting that mediators specifically released by mast cell degranulation induced metabolic alterations of the lens epithelium and/or disruption of epithelial tight junctions, altering the lens homeostasis and inducing lens opacity. ${ }^{36}$ In addition to the anterior segment inflammation induced by compound $48 / 80$, choroidal mast cell degranulation provoked posterior segment disease. Indeed, subconjunctival injection of drug also follows a transscleral route, ${ }^{37}$ allowing a massive degranulation of choroidal mast cells.

As early as 1 hour after compound 48/80 injection, SRDs were observed. These lesions persisted in severity (area and height) with time up to 6 to 7 hours as observed with in vivo OCT imaging. However, spectral domain OCT performed in rats, with an optimized lens, does not provide OCT images with a resolution comparable with images obtained in humans. Nevertheless, retinal layers could be observed with good repeatability. ${ }^{38}$

On histologic sections, choroidal thickening and choroidal vessel dilation was observed quickly after compound 48/80 injection, followed by RPE barrier disruption and SRDs, which were associated with numerous RPE cell defects. The notably short time from mast cells degranulation until RPE barrier breakdown suggests direct junction destabilization by the released mediators. Histamine was shown to induce tightjunction opening in corneal endothelial cells ${ }^{39}$ and in retinal 

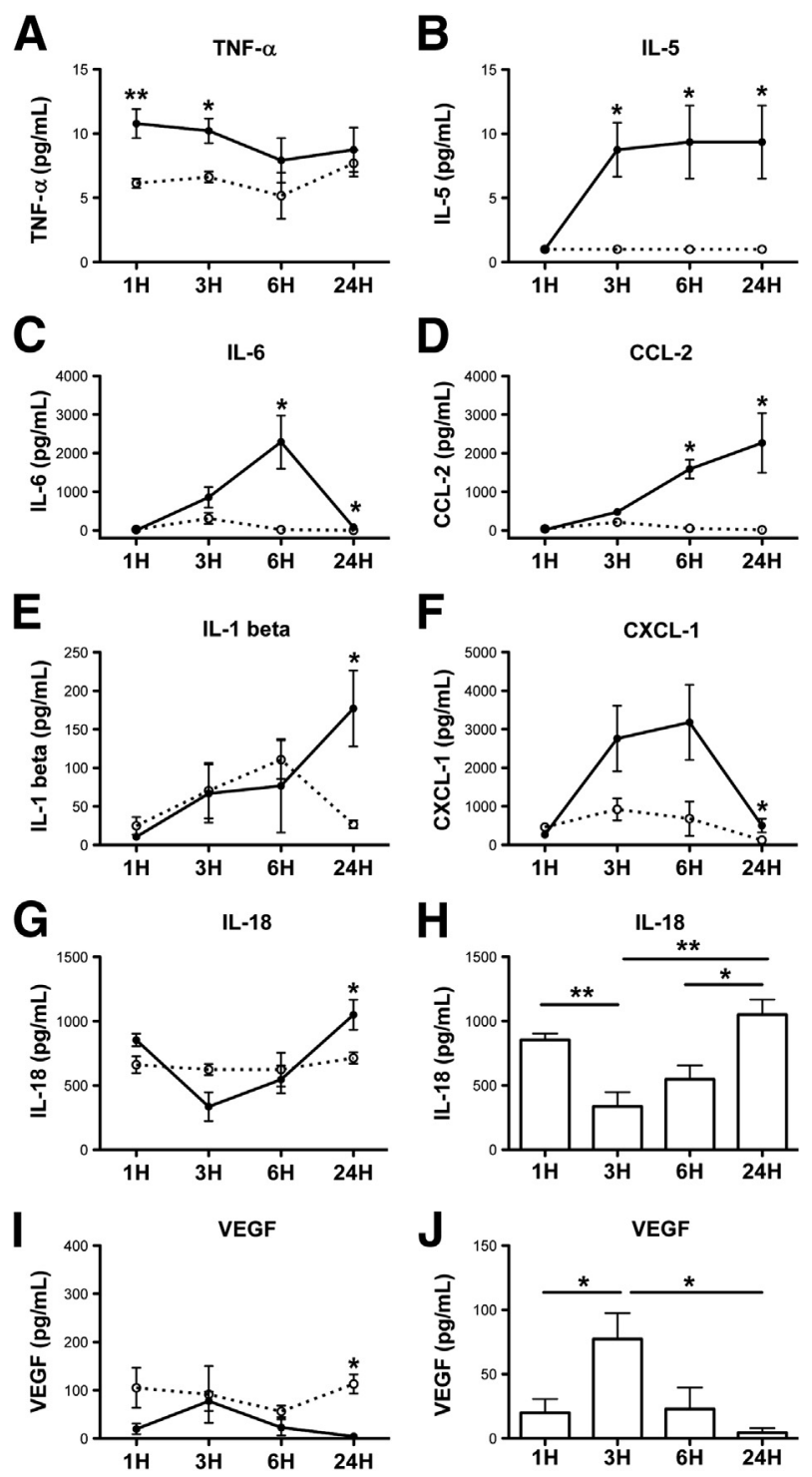

Figure 8 Time course of intraocular cytokine and chemokine concentrations after subconjunctival injection of compound 48/80 (closed circles; control, open circles). A: TNF- $\alpha$ increased at 1 hour and 3 hours after compound 48/80 injection compared with sodium chloride-injected eyes. B-D: A significant upregulation of IL-5 at 3, 6, and 24 hours is observed in compound 48/80-injected eyes (B), together with an up-regulation of IL-6 and CCL-2 at 6 and 24 hours (C and D) compared with sodium chloride-injected eyes. E-I: An increase of IL-1 $\beta$ and CXCL-1 (E and $\mathbf{F}$ ) was detected at 24 hours. A significant increase of IL-18 (G) and a significant decrease of VEGF (I) occurs at 24 hours in compound 48/80-injected eyes. $\mathbf{H}$ and J: The course of concentrations of IL-18 (H) and VEGF (J) in compound 48/80-injected eyes shows an opposite trend. At 3 hours, IL-18 significantly decreases compared with its concentrations at 1 hour, whereas VEGF significantly increases compared with its concentrations at 1 hour. In contrast compared with concentrations at 3 hours, at 6 and 24 hours IL-18 significantly increases, whereas VEGF significantly decreases. $n=4$ to 6 compound 48/ 80 -injected eyes per time point; $n=5$ to 6 sodium chloride-injected eyes (control) per time point. ${ }^{*} P<0.05,{ }^{*} P<0.01$. CCL, chemokine ligand; TNF, tumor necrosis factor; VEGF, vascular endothelial growth factor.

vascular endothelium. ${ }^{40}$ Histamine administered intravenously also increased choroidal blood flow as evaluated by laser Doppler scanning in humans. ${ }^{41}$ Whether histamine induces direct effects on RPE tight junctions or whether it is a consequence of other inflammatory mediators has not yet been explored.

Mast cells have a large catalog of cell surface receptors, such as IgE receptors, complement component receptors, and various Toll-like receptors. Moreover, mast cells respond to a large variety of stimuli ${ }^{42}$ and induce the synthesis of TNF- $\alpha$ and IL- $6 .{ }^{43}$ In the present study, TNF- $\alpha$ was the first cytokine to be upregulated in the eye (1 hour after compound 48/80 injection), followed by IL- 6 ( 6 hours), confirming that TNF- $\alpha$ could induce IL-6 release during ocular inflammation. ${ }^{44}$ It is understood that TNF- $\alpha$ can contribute to the outer retinal barrier breakdown, because rat RPE cell monoculture co-incubated with TNF- $\alpha$ together with lipopolysaccharide + interferon $-\gamma$ altered RPE tight junctions with abnormal distribution of zonula occludens. ${ }^{45}$

Experimental ocular inflammation is characterized by the breakdown of blood-ocular barriers that allow inflammatory cells, including macrophages and polymorphonuclear leukocytes, to invade the ocular tissues. ${ }^{46}$ Mast cells also modulate neutrophil influx and recruit neutrophils through TNF- $\alpha$ release. ${ }^{47}$ The injection of human recombinant IL-6 into the vitreous was reported to induce an accumulation of neutrophils in the anterior and posterior segments of the eye. ${ }^{48}$ Further, in the present situation, the rat chemokine CXCL-1 (a neutrophil chemoattractant) was also substantially increased and responsible, together with TNF- $\alpha$ and IL-6, for the neutrophil infiltration of the anterior chamber. These different mediators, successively produced, allowed the neutrophil infiltration observed after compound 48/80 injection in the eye.

Further, IL-18, a potent neutrophil-activating factor, ${ }^{49,50}$ was augmented after compound 48/80 injection with an opposite regulation of the concentrations of VEGF. At 24 hours, substantially higher concentrations of IL-18 and lower concentrations of VEGF were observed in compound 48/80-injected rats compared with contralateral eyes. The exact role of IL-18 in the eye is still unclear, ${ }^{51}$ but VEGF and IL-18 were shown to suppress each other's production. ${ }^{52}$ In a mouse model of neovascularization, ${ }^{53}$ IL-18 inhibited new vessel formation but promoted damage to the RPE that mimics aspects of the dry form of AMD. ${ }^{54}$ Alteration of RPE cells after mast cell degranulation could thus be at least in part related to IL-18 increase.

This study shows for the first time that mast cell degranulation induces choroidal, RPE, and retinal disorders that result in SRD, a sign common to various retinal diseases. Development of spectral domain OCT by using enhanced depth imaging module has allowed identifying a wide spectrum of chorioretinal diseases associated with pachychoroid (choroidal thickening) such as central serous chorioretinopathy and polypoidal choroidal vasculopathy. ${ }^{55}$ Whether mast cell degranulation could be involved in such conditions should be explored. Because mast cells progressively reconstitute their granules evokes that, if the stimulus persists, successive degranulation could lead to the breakdown of chronic barriers and accumulation of subretinal fluid. In AMD, complement activation leads to C5a accumulation in the choroid, which could also induce mast cell degranulation ${ }^{30}$ potentially contributing to rupture of the retinal epithelium barrier. 


\section{Conclusion}

Because factors that trigger or result from mast cell degranulation are identified in the pathogenesis of many a priori noninflammatory diseases, including AMD, we suggest that mast cell degranulation could be an important factor in chronic ocular diseases and in acute ocular inflammation. Pharmacologic inhibition of mast cell degranulation by inhibiting the release of inflammatory mediators could have an important therapeutic potential on retinal diseases associated with choroidal enlargement and/or SRDs.

\section{References}

1. McMenamin PG, Polla E: Mast cells are present in the choroid of the normal eye in most vertebrate classes. Vet Ophthalmol 2013, 16(Suppl 1):73-78

2. Larsen G: The mast cells in the uveal tract of the eye and changes induced by hormones and avitaminosis-C. Am J Ophthalmol 1959, 47:509-519

3. Steptoe RJ, McMenamin C, McMenamin PG: Choroidal mast cell dynamics during experimental autoimmune uveoretinitis in rat strains of differing susceptibility. Ocul Immunol Inflamm 1994, 2:7-22

4. de Kozak Y, Sainte-Laudy J, Benveniste J, Faure JP: Evidence for immediate hypersensitivity phenomena in experimental autoimmune uveoretinitis. Eur J Immunol 1981, 11:612-617

5. Levene RZ: Mast cells and amines in normal ocular tissues. Invest Ophthalmol 1962, 1:531-543

6. Galli SJ, Grimbaldeston M, Tsai M: Immunomodulatory mast cells: negative, as well as positive, regulators of immunity. Nat Rev Immunol 2008, 8:478-486

7. Sandig H, Bulfone-Paus S: TLR signaling in mast cells: common and unique features. Front Immunol 2012, 3:185

8. Galli SJ, Tsai M: IgE and mast cells in allergic disease. Nat Med 2012, 18:693-704

9. Wershil BK, Wang ZS, Gordon JR, Galli SJ: Recruitment of neutrophils during IgE-dependent cutaneous late phase reactions in the mouse is mast cell-dependent. Partial inhibition of the reaction with antiserum against tumor necrosis factor-alpha. J Clin Invest 1991, 87: 446-453

10. Caspi RR: A look at autoimmunity and inflammation in the eye. J Clin Invest 2010, 120:3073-3083

11. Wildner G, Diedrichs-Möhring M: Autoimmune uveitis and antigenic mimicry of environmental antigens. Autoimmun Rev 2004, 3:383-387

12. De Kozak Y, Sakai J, Sainte-Laudy J, Faure JP, Benveniste J: Pharmacological modulation of IgE-dependent mast cell degranulation in experimental autoimmune uveoretinitis. Jpn J Ophthalmol 1983, 27:598-608

13. Smith JR, Hart PH, Coster DJ, Williams KA: Uveal mast cells are not required for rodent uveitis. Ophthalmic Res 1998, 30:388-393

14. da Silva PS, Girol AP, Oliani SM: Mast cells modulate the inflammatory process in endotoxin-induced uveitis. Mol Vis 2011, 17: $1310-1319$

15. Mochizuki M, Kuwabara T, Chan CC, Nussenblatt RB, Metcalfe DD, Gery I: An association between susceptibility to experimental autoimmune uveitis and choroidal mast cell numbers. J Immunol 1984, 133:1699-1701

16. Li Q, Whitcup SM, Fujino Y, Nussenblatt RB, Chan CC: The role of mast cells in endotoxin-induced uveitis. Invest Ophthalmol Vis Sci 1993, 34:256-259

17. Lee DM, Friend DS, Gurish MF, Benoist C, Mathis D, Brenner MB: Mast cells: a cellular link between autoantibodies and inflammatory arthritis. Science 2002, 297:1689-1692
18. Walker ME, Hatfield JK, Brown MA: New insights into the role of mast cells in autoimmunity: evidence for a common mechanism of action? Biochim Biophys Acta 2012, 1822:57-65

19. Paton WD: Compound 48/80: a potent histamine liberator. $\mathrm{Br} \mathrm{J}$ Pharmacol Chemother 1951, 6:499-508

20. Eglezos A, Lecci A, Santicioli P, Giuliani S, Tramontana M, Del Bianco E, Maggi CA: Activation of capsaicin-sensitive primary afferents in the rat urinary bladder by compound 48/80: a direct action on sensory nerves? Arch Int Pharmacodyn Thér 1992, 315:96-109

21. Heppner TJ, Fiekers JF: Compound 48/80 blocks transmission and increases the excitability of ganglion neurons. Eur J Pharmacol 1992, 213:427-434

22. Schemann M, Kugler EM, Buhner S, Eastwood C, Donovan J, Jiang W, Grundy D: The mast cell degranulator compound 48/80 directly activates neurons. PLoS One 2012, 7:e52104

23. Chatterjea D, Wetzel A, Mack M, Engblom C, Allen J, MoraSolano C, Paredes L, Balsells E, Martinov T: Mast cell degranulation mediates compound 48/80-induced hyperalgesia in mice. Biochem Biophys Res Commun 2012, 425:237-243

24. Nakai K, Gomi F, Ikuno Y, Yasuno Y, Nouchi T, Ohguro N, Nishida K: Choroidal observations in Vogt-Koyanagi-Harada disease using high-penetration optical coherence tomography. Graefes Arch Clin Exp Ophthalmol 2012, 250:1089-1095

25. Marmor M: On the cause of serous detachments and acute central serous chorioretinopathy. Br J Ophthalmol 1997, 81:812-813

26. Takeda A, Baffi JZ, Kleinman ME, Cho WG, Nozaki M, Yamada K, Kaneko H, Albuquerque RJ, Dridi S, Saito K, Raisler BJ, Budd SJ, Geisen P, Munitz A, Ambati BK, Green MG, Ishibashi T, Wright JD, Humbles AA, Gerard CJ, Ogura Y, Pan Y, Smith JR, Grisanti S, Hartnett ME, Rothenberg ME, Ambati J: CCR3 is a target for agerelated macular degeneration diagnosis and therapy. Nature 2009, 460:225-230

27. Tuo J, Grob S, Zhang K, Chan CC: Genetics of immunological and inflammatory components in age-related macular degeneration. Ocul Immunol Inflamm 2012, 20:27-36

28. Anderson DH, Radeke MJ, Gallo NB, Chapin EA, Johnson PT, Curletti CR, Hancox LS, Hu J, Ebright JN, Malek G, Hauser MA, Rickman CB, Bok D, Hageman GS, Johnson LV: The pivotal role of the complement system in aging and age-related macular degeneration: hypothesis re-visited. Prog Retin Eye Res 2010, 29:95-112

29. Schäfer B, Piliponsky AM, Oka T, Song CH, Gerard NP, Gerard C, Tsai M, Kalesnikoff J, Galli SJ: Mast cell anaphylatoxin receptor expression can enhance IgE-dependent skin inflammation in mice. J Allergy Clin Immunol 2013, 131. 541-548.e1-9

30. Nozaki M, Raisler BJ, Sakurai E, Sarma JV, Barnum SR, Lambris JD, Chen Y, Zhang K, Ambati BK, Baffi JZ, Ambati J: Drusen complement components $\mathrm{C} 3 \mathrm{a}$ and $\mathrm{C} 5 \mathrm{a}$ promote choroidal neovascularization. Proc Natl Acad Sci U S A 2006, 103:2328-2333

31. Fischer MD, Huber G, Beck SC, Tanimoto N, Muehlfriedel R, Fahl E, Grimm C, Wenzel A, Remé CE, van de Pavert SA, Wijnholds J, Pacal M, Bremner R, Seeliger MW: Noninvasive, in vivo assessment of mouse retinal structure using optical coherence tomography. PLoS One 2009, 4:e7507

32. Spaide RF, Koizumi H, Pozzoni MC: Enhanced depth imaging spectral-domain optical coherence tomography. Am J Ophthalmol 2008, 146:496-500

33. Omri S, Behar-Cohen F, de Kozak Y, Sennlaub F, Verissimo LM, Jonet L, Savoldelli M, Omri B, Crisanti P: Microglia/macrophages migrate through retinal epithelium barrier by a transcellular route in diabetic retinopathy: role of PKC $\zeta$ in the Goto Kakizaki rat model. Am J Pathol 2011, 179:942-953

34. Zhao M, Célérier I, Bousquet E, Jeanny JC, Jonet L, Savoldelli M, Offret O, Curan A, Farman N, Jaisser F, Behar-Cohen F: Mineralocorticoid receptor is involved in rat and human ocular chorioretinopathy. J Clin Invest 2012, 122:2672-2679

35. Ts'o MO, Friedman E: The retinal pigment epithelium. 3. Growth and development. Arch Ophthalmol 1968, 80:214-216 
36. Candia OA: Electrolyte and fluid transport across corneal, conjunctival and lens epithelia. Exp Eye Res 2004, 78:527-535

37. Kim TW, Lindsey JD, Aihara M, Anthony TL, Weinreb RN: Intraocular distribution of 70-kDa dextran after subconjunctival injection in mice. Invest Ophthalmol Vis Sci 2002, 43:1809-1816

38. Berger A, Cavallero S, Dominguez E, Barbe P, Simonutti M, Sahel JA, Sennlaub F, Raoul W, Paques M, Bemelmans AP: Spectraldomain optical coherence tomography of the rodent eye: highlighting layers of the outer retina using signal averaging and comparison with histology. PLoS One 2014, 9:e96494

39. Srinivas SP, Satpathy M, Guo Y, Anandan V: Histamine-induced phosphorylation of the regulatory light chain of myosin II disrupts the barrier integrity of corneal endothelial cells. Invest Ophthalmol Vis Sci 2006, 47:4011-4018

40. Gardner TW, Lesher T, Khin S, Vu C, Barber AJ, Brennan WA Jr: Histamine reduces ZO-1 tight-junction protein expression in cultured retinal microvascular endothelial cells. Biochem J 1996, 320(Pt 3): 717-721

41. Zawinka C, Resch H, Schmetterer L, Dorner GT, Garhofer G: Intravenously administered histamine increases choroidal but not retinal blood flow. Invest Ophthalmol Vis Sci 2004, 45:2337-2341

42. Abraham SN, St John AL: Mast cell-orchestrated immunity to pathogens. Nat Rev Immunol 2010, 10:440-452

43. Marshall JS, Jawdat DM: Mast cells in innate immunity. J Allergy Clin Immunol 2004, 114:21-27

44. de Vos AF, van Haren MA, Verhagen C, Hoekzema R, Kijlstra A: Kinetics of intraocular tumor necrosis factor and interleukin-6 in endotoxin-induced uveitis in the rat. Invest Ophthalmol Vis Sci 1994, 35:1100-1106

45. Zech JC, Pouvreau I, Cotinet A, Goureau O, Le Varlet B, de Kozak Y: Effect of cytokines and nitric oxide on tight junctions in cultured rat retinal pigment epithelium. Invest Ophthalmol Vis Sci 1998, 39:1600-1608

46. de Kozak Y, Omri B, Smith JR, Naud MC, Thillaye-Goldenberg B, Crisanti P: Protein kinase Czeta (PKCzeta) regulates ocular inflammation and apoptosis in endotoxin-induced uveitis (EIU): signaling molecules involved in EIU resolution by PKCzeta inhibitor and interleukin-13. Am J Pathol 2007, 170:1241-1257

47. Malaviya R, Ikeda T, Ross E, Abraham SN: Mast cell modulation of neutrophil influx and bacterial clearance at sites of infection through TNF-alpha. Nature 1996, 381:77-80

48. Hoekzema R, Verhagen C, van Haren M, Kijlstra A: Endotoxininduced uveitis in the rat. The significance of intraocular interleukin6. Invest Ophthalmol Vis Sci 1992, 33:532-539

49. Leung BP, Culshaw S, Gracie JA, Hunter D, Canetti CA, Campbell C, Cunha F, Liew FY, McInnes IB: A role for IL-18 in neutrophil activation. J Immunol 2001, 167:2879-2886

50. Robertson SE, Young JD, Kitson S, Pitt A, Evans J, Roes J, Karaoglu D, Santora L, Ghayur T, Liew FY, Gracie JA, McInnes IB: Expression and alternative processing of IL-18 in human neutrophils. Eur J Immunol 2006, 36:722-731

51. Rosenbaum JT: Eyeing macular degeneration-few inflammatory remarks. N Engl J Med 2012, 367:768-770

52. Shen J, Choy DF, Yoshida T, Iwase T, Hafiz G, Xie B, Hackett SF, Arron JR, Campochiaro PA: Interleukin-18 has antipermeablity and antiangiogenic activities in the eye: reciprocal suppression with VEGF. J Cell Physiol 2014, 229:974-983

53. Doyle SL, Campbell M, Ozaki E, Salomon RG, Mori A, Kenna PF, Farrar GJ, Kiang AS, Humphries MM, Lavelle EC, O'Neill LA, Hollyfield JG, Humphries P: NLRP3 has a protective role in agerelated macular degeneration through the induction of IL-18 by drusen components. Nat Med 2012, 18:791-798

54. Tarallo V, Hirano Y, Gelfand BD, Dridi S, Kerur N, Kim Y, Cho WG, Kaneko H, Fowler BJ, Bogdanovich S, Albuquerque RJ, Hauswirth WW, Chiodo VA, Kugel JF, Goodrich JA, Ponicsan SL, Chaudhuri G, Murphy MP, Dunaief JL, Ambati BK, Ogura Y, Yoo JW, Lee DK, Provost P, Hinton DR, Núñez G, Baffi JZ, Kleinman ME, Ambati J: DICER1 loss and Alu RNA induce agerelated macular degeneration via the NLRP3 inflammasome and MyD88. Cell 2012, 149:847-859

55. Warrow DJ, Hoang QV, Freund KB: Pachychoroid pigment epitheliopathy. Retina (Phila Pa) 2013, 33:1659-1672 